\title{
LA REVOLUCIÓN DE INTERNET
}

\section{THE INTERNET REVOLUTION}

\author{
Eduardo Alberto Montes Farro*
}

Docente Asociado de la Facultad de Ciencias Contables

[Recepción: Agosto de 2010/ Conformidad: Setiembre de 2010]

\section{RESUMEN}

Cuando Alvin Toffler presagiaba la Tercera Ola de la civilización, ya señalaba la importancia de la información.

Bueno, el tiempo le ha dado la razón; y se puede aceptar que ya estamos viviendo una nueva era. La herramienta fundamental para este hecho se denomina Internet, cuyas características se están aplicando en múltiples actividades; y no acaba de desarrollarse.

Si tomamos como ejemplo la gestión empresarial, que implica la participación activa de todas las áreas de la organización, donde la información constituye un recurso imprescindible, al utilizar los servicios de Internet, se puede apreciar cómo ejerce su influencia, determinando un poderoso impacto en toda la vida de la sociedad.

En este entorno, el profesional contable, como generador de información, tiene una relevante participación y aporte en el conocimiento y la gestión empresarial.

Palabras clave: Revolución de la información. Teoría y Sistemas de Información, Virtual, informático, digital, electrónico, Competitividad de la Información, Tiempo, Distancia.

\begin{abstract}
When Alvin Toffler foreshadowed the Third Wave civilization, and $\mathrm{n}$ ted the importance of information.

Well, time has proved right, and you can accept that we are witnessing a new era. The basic tool for this fact is called the Internet, whose features are being implemented in many activities, and not just develop.

Taking the example of management, which involves active participation from all areas of the organization, where information is an essential resource, using Internet services, you can see how it exercises its influence, identifying a powerful impact on all life of society. In this environment, the accounting professional, a generator of information, have a significant participation and contribution to knowledge and business management.
\end{abstract}

Keywords: Information Revolution. Theory and Information Systems, Virtual, computer, digital, electronic, Competitiveness of the Information, Time, Distance.

* Contador Público Colegiado Certificado. Docente Investigador de la Facultad de Ciencias Contables, UNMSM. Docente Asociado de la Facultad de Ciencias Contables, UNMSM.

E- mail: amontesfa1@yahoo.es 


\section{INTRODUCCIÓN}

Actualmente la mayoría de población del mundo ya tiene una idea de lo que es Internet. Aunque los niveles de comprensión y de uso, todavía, son bastante restringidos.

Sin embargo ya se puede aseverar que nos ha tocado vivir una era de cambios y transformaciones, y una buena parte de ellos se debe en gran medida al surgimiento y apogeo de la Red de redes: Internet.

La tecnología de la información (TI) está logrando lo que ningún medio pudo hacer antes: comunicar e informar a los seres humanos instantáneamente, con calidad, sin considerar las distancias y a muy poco costo.

Podemos afirmar que Internet se ha instalado en el presente y propiciará los lineamientos del futuro.

Cuando nos preguntamos sobre el significado del Internet en la sociedad actual, se puede resumir sus efectos como una revolución radical en la sociedad. En este artículo hacemos un rápido recorrido sobre este hecho.

\subsection{Origen de Internet}

Internet es sin duda uno de los inventos más significativos del siglo XX. Puede cambiar la forma de comunicarse con otras personas, ya que se perfila como el medio para conseguir entretenimiento, noticias, realizar transacciones y trabajar a distancia.

Es consecuencia de la reunión de los resultados en distintos campos de investigación: redes de comunicaciones, protocolos, software de navegación por la red, etc., que, según la mayoría de los expertos opinan que Internet nació en enero de 1983.

Se originó a partir de un proyecto exclusivamente militar, en 1969, denominado ARPANET (Advanced Research Projects Agency Network), con el objetivo de mantenerse informado sobre un posible ataque bélico.
Debido al rápido crecimiento de la red, su sistema de comunicación quedó obsoleto. Entonces fue creado el Protocolo TCP/IP (Transmission Control Protocol/Internet Protocol), en 1974, que se convirtió en el estándar de comunicaciones dentro de las redes informáticas.

Posteriormente, la NSF (National Science Fundation) crea su propia red informática llamada NSFNET, más tarde absorbe a ARPANET, estableciendo una gran red con propósitos científicos y académicos, se crean nuevas redes de libre acceso que se unen a NSFNET, formando el embrión de lo que hoy conocemos como INTERNET.

Con el incremento del uso de los hipervínculos con el lenguaje hipertexto, surge la posibilidad de "navegar" en el "ciberespacio".

Así, sucesivamente, con el desarrollo de aplicativos, se ha ido incrementando las posibilidades de intercambio de información y comunicación, que no se detiene.

\section{EL INTERNET Y EL SER HUMANO}

Por la dinámica que vive el mundo debido al desarrollo de Internet, en sus múltiples manifestaciones y aplicaciones, se puede afirmar que ya estamos, por lo menos en sus inicios, en una nueva era o civilización.

Internet es un poderoso instrumento de comunicación y transformación en todas las actividades del ser humano.

Puedo referirme, como ilustración, al ambiente empresarial. Una editorial: Prentice Hall tiene una colección o serie "Mentes con visión de futuro", que da la bienvenida a la "nueva generación de negocios" donde afirma: "Un nuevo mundo en el que las fuerzas de la tecnología y la innovación están cambiando radicalmente nuestra manera de trabajar y hacer negocios". Afirma, además: "Entendemos que la llave del éxito no 
está en la misma tecnología, si no en la gente que la usa”.

Peter Drucker en su libro La Gerencia en la Sociedad Futura, comenta lo siguiente:

Apenas ahora empezamos a sentir el verdadero efecto de la revolución informática, pero no es la "información" lo que produce ese efecto, ni es la "inteligencia artificial".

Es algo que nadie podía prever y de lo cual ni siquiera se hablaba hace diez o quince años: el comercio electrónico, es decir, la aparición explosiva de la Internet como importante canal de distribución de bienes y servicios - tal vez el más importante de todos $-\mathrm{y}$, sorprendentemente, de empleos gerenciales y profesionales. Esto está cambiando a fondo las economías, los mercados y las estructuras industriales; los productos y servicios y su flujo; la segmentación de los consumidores, sus valores y su conducta; los mercados de empleos y de mano de obra”.

"En particular, se da por sabido que la revolución informática será como la revolución industrial de fines del siglo XVIII y comienzos del XIX. Y así es justamente como la revolución informática se ha comportado en sus primeros cincuenta años".

El Internet ha logrado imponerse con mayor rapidez en comparación a la escritura y la imprenta. La Web está acompañada de un ritmo de cambios acelerados y sin interrupciones, sus alcances son ilimitados y, actualmente, quien no se incorpora a la Red navega contra la corriente del éxito.

El Internet es un instrumento que facilita a las personas el rápido acceso a cantidades infinitas de información, a un costo relativamente bajo, sobre cualquier índole y proveniente de cualquier rincón del mundo, por esta razón se habla de la Sociedad de la Información. El Internet nos permite acercarnos en cuestión de nano segundos o micro se- gundos a sitios y lugares virtuales y recabar información que antes sólo se lograba con gran esfuerzo. Internet crece cada vez más y el mundo analógico se hace cada vez más pequeño, convirtiéndose en una aldea digital.

La historia humana de hoy se caracteriza por términos como informático, digital, electrónico, virtual, computarizado; y tiene como protagonista a la Web: una Red de redes, hacen de esta una verdadera revolución.

Ahora bien, como la Red es una infraestructura que ofrece espacio hasta para las más simples y complejas tareas de la vida, los medios de comunicación social no escapan a formar parte de ese ambiente de "infinita globalidad”.

\section{EL INTERNET COMO MEDIO DE COMUNICACIÓN Y DE INFORMACIÓN}

El Internet, es mucho más que un medio de comunicación de masas, porque ciertamente un mismo mensaje puede enviarse al mismo tiempo a una gran cantidad de personas, pero no todas las personas sabrán de él al mismo tiempo - si se trata de un email cada quien leerá el mensaje al revisar su Bandeja de Correos - y cada persona tendrá en sus manos la decisión de leerlo o no. Así también, los contenidos de un Sitio Web están al alcance de todos, pero cada individuo puede buscar entre toda la información que se le ofrezca sólo la que le resulte interesante. Es una especie de gran contenedor en el que caben todos los medios que hemos conocido hasta ahora. Internet no sería entonces un medio sino solo el canal: como el aire por el cual circulan todas las ondas, permite en su particular ambiente la combinación de todos los demás medios. En la Red están la escritura y la fotografía de la prensa, las 
imágenes en video de la televisión y el sonido de la radio, sumados a la interacción y personalización de mensajes.

A groso modo, se pueden identificar algunas peculiaridades que hacen a Internet un fenómeno en cuanto a comunicación: Interactiva, Universal, Simultánea, Inmediata, Integradora, Libre, Actualizable, Personalizada. El Internet se convierte en el espacio ideal para las comunicaciones del futuro y los medios tradicionales salen perdiendo. Hasta ahora la aparición de una nueva forma o tecnología de comunicación no ha significado la desaparición de lo ya existente. Inclusive, ya está dicho que los medios tradicionales se reconstituyen con Internet, porque están obligados a revisarse y potenciar sus ventajas y características únicas.

El Internet es un soporte que así como ofrece innumerables ventajas exige peculiares condiciones. Esto supone que quienes desde un medio de comunicación tradicional se conforman con ver en Internet un simple instrumento de promoción, o un canal de transmisión para mayor cobertura, pierden dinero y tiempo. Porque los denominados medios paralelos (prensa, radio o televisión en línea) son precisamente otros medios, soportados en los tradicionales pero con características propias por demás potenciales que, bien aprovechadas, garantizan rentabilidad y competitividad.

Tomando como base una afirmación hecha anteriormente, la cual señala que Internet es el soporte de nuevos medios de comunicación, no puede consentirse que los medios tradicionales expongan una copia de sí mismos en la Web. Porque la Red, por ser un metamedio, posee características singulares que requieren que las formas y contenidos a exponer en ella se adapten a sus peculiaridades, sobre todo para que resulte provechoso.

\section{EL INTERNET Y LA TERCERA OLA}

La Tercera Ola de Toffler, cuyo impacto apenas estamos empezando a calibrar en este principio del siglo XXI, traerá cambios de enorme magnitud en la sociedad, la economía y la política.

Internet el principal sistema de la Infoesfera, haciendo mover los flujos de información a gran velocidad, incluye toda una serie de tecnologías que vienen incubándose desde la Segunda Guerra Mundial, los microprocesadores en chips, la memoria magnética, los ordenadores digitales y las redes de información abiertas, que en combinación se están convirtiendo en un sistema de difusión de información transformacional con respecto al paradigma de la era anterior.

Cualquier persona con un nivel medio de formación y económico tiene la capacidad de publicar sin interferencia alguna en una red de alcance mundial, hacer copias perfectas de cualquier obra digitalizada, lo cual significa de cualquier información. Los sistemas artificiales de limitación, como el 'copyright', el Derecho de Autor o las protecciones tecnológicas contra la copia, acaban siendo irrelevantes.

Es este factor el que provoca el desmesurado crecimiento de la información disponible, yla preocupación por sus efectos nocivos. Pero se trata de un simple efecto secundario. El carácter revolucionario del conjunto de tecnologías que llamamos Internet es la posibilidad de publicar (casi) sin límites. No hay pues diferencia entre el coste individual de una copia entre 10 o entre un millón.

Internet consiste actualmente en millones de computadores en todo el mundo unidos entre sí, a través de los cuáles pueden intercambiarse, a bajo costo, textos, imágenes, voz y vídeo. Sin duda, ésta es la mayor 
revolución, facilita la comunicación entre seres humanos, rompiendo las barreras del tiempo y la distancia y, hasta cierto punto, las del lenguaje. Estos millones de computadores interconectados pueden verse como uno solo gigantesco en su potencia de cálculo, en su capacidad de almacenamiento y en las facilidades que proporciona para que las personas se comuniquen.

La tercera ola amplifica la comunicación entre personas. Hasta ahora, la tendencia era al agigantamiento de nuestro ordenador personal: cada vez debía ser más potente, tener más memoria y más capacidad de almacenamiento en disco. Una consecuencia inesperada de la tercera ola es la ruptura de esa tendencia. Si los programas interesantes los tiene la "red", así como una enorme potencia de cálculo y de almacenamiento, ¿para qué necesitamos un computador cada vez más grande en nuestra casa? La respuesta es que para nada. Por primera vez se rompe la tendencia hacia el agigantamiento. Un sencillo computador puede darnos el servicio adecuado.

Sin embargo, serviría tener en cuenta lo dicho por Dretske, Fred I., en su libro Conocimiento e Información:

"La información que contiene una señal (lingüística o de otro tipo) sólo está relacionada con su significado (si es que lo tiene) de una manera accidental. Normalmente, por supuesto, nos comunicamos, intercambiamos información explotando el significado convencional de los signos. Expresamos información usando signos que tienen un significado que corresponde a !a información que queremos expresar. Pero eso no debe hacernos confundir el significado de un símbolo con la información, o cantidad de información que lleva"

También añade: "Así, según este uso del término, las señales pueden tener un significado, pero llevan información. La información que lleva una señal es lo que nos puede "decir", lo que nos puede decir con verdad, sobre otro estado de cosas. En general, la información nos puede proporcionar conocimiento y la información que lleva es lo que podemos saber gracias a ella. Si todo lo que yo le digo a alguien es falso, no le he dado ninguna información", queriendo aclarar la diferencia que existe entre los términos comunicación e información.

Examinando la situación empresarial, es necesario replantearse las preguntas fundamentales con respecto a la información. ¿Cuándo la necesito? ¿De quién? ¿Qué información debo dar?

Según Peter Drucker: "La mayoría de la empresas tienen dos sistemas de información. Uno organizado en torno a los datos que llegan continuamente; el otro en torno al sistema contable. Pero este último es un sistema de información que tiene 500 años de existencia y que está en muy mala forma”.

"Los cambios que veremos en las tecnologías de la información en los próximos 20 años no son nada comparados con los que veremos en la contabilidad".

Y reflexiona además: "El ferrocarril, inventado en 1829, dominó las distancias. Esto explica por qué más que cualquier otra de las invenciones de la Revolución Industrial, cambió la economía y la fuerza laboral de todas las naciones. Varió la mentalidad de la humanidad, sus horizontes, su "geografía mental". El comercio electrónico no se limita a dominar las distancias, las elimina”.

Como decíamos anteriormente, la Tecnología de la Información (TI) está logrando lo que ningún medio pudo hacer antes: comunicar e informar a los seres humanos instantáneamente, con calidad, sin considerar las distancias y a muy poco costo.

Es muy cierto y evidente, pero queremos señalar que actualmente disponemos de muchísima tecnología, que seguirá inno- 
vándose; pero que sobre la Información, se tiene que revisar y revalorar la Teoría de la Información. Podría confundirse que los mensajes que se intercambien en el mundo, se considere información, siendo tan sólo comunicación, muy útil por supuesto.

Este segundo concepto, la Información, de las Tecnología de la Información (TI ), requiere de una mayor atención; y no sólo eso, sino saber qué hace o que hará el ser humano con la Información disponible.

Tema que consideramos de lo más relevante para el futuro de la humanidad.

\section{CONCLUSIONES}

1. Las oportunidades y desafíos que se desprenden de Internet para la comunicación social son tan infinitas como ese mundo que va creciendo en la Web. Cómo el ser humano se enfrentará a su futuro. Será una perspectiva apasionante $y$ todo un reto para los años venideros.

2. El Internet y las Tecnologías de Información han afectado o cambiado la comunicación social, porque es evidente que la obligan constantemente a cambiar, así como lo hacen con el resto de las actividades que el hombre desarrolla en el mundo.

3. Se debe asumir con responsabilidad la tarea de mirar todas las innovaciones tecnológicas que surgen en el área de información y comunicación desde una perspectiva más amplia, porque es imposible ya mirar desde afuera.

4. Ya no puede dudarse que los medios de comunicación forman parte de las tec- nologías de información y que a su vez, en acción complementaria, mejoran con cada invención que surge en el área. Tampoco hay duda de las oportunidades que surgen para los comunicadores sociales en este nuevo orden mundial que impone la llamada Revolución de la Información.

\section{REFERENCIAS BIBLIOGRÁFICAS}

1. Aghion, P. y Howitt, P. (1998), Endogenous Growth Theory, Cambridge, MA: MIT Press.

2. Conocimiento e Información, Fred I. Dretske, Biblioteca Científica Salvat.

3. El viaje de la innovación empresarial, Oscar Peña de San Antonio, Prentice Hall.

4. La Tercera Ola, Alvin Toffler, P\&J.

5. El Shock del futuro, Alvin Toffler, P\&J

6. Banda Ancha Exprimida, Agustín Capeletto, MP Ediciones.

7. Nueva Economía y Nueva Sociedad, Andrés Suárez Suárez, Prentice Hall.

8. La empresa en la sociedad que viene, Peter F. Drucker, Harvard Business Review

9. Descubre internet, Jesús Carretero y otros, Prentice Hall.

10. El Mundo de Internet, Editorial Macro

11. CODESI, Estrategia Nacional de Gobierno Electrónico, Lima, Jul 2006 [Versión electrónica] Fecha de consulta: 10/10/2009. Huidobro, J y Roldán D, "La tecnología e-business", España, 2005, PARANINFO.

12. Laurence Wolff, Acceso de alta velocidad al Internet: El futuro del mundo y sus implicaciones para los países en desarrollo, Oct 1999, Scientific American. 